Pure Appl. Chem., Vol. 84, No. 11, pp. 2431-2441, 2012.

http://dx.doi.org/10.1351/PAC-CON-12-01-08

(C) 2012 IUPAC, Publication date (Web): 24 June 2012

\title{
Complexity-generating hydration reactions via gold-catalyzed addition of boronic acids to alkynes*
}

\author{
Tom D. Sheppard $\ddagger$ \\ Department of Chemistry, University College London, Christopher Ingold \\ Laboratories, 20 Gordon St, London, WC1H OAJ, UK
}

\begin{abstract}
Boronic acids can serve as organic soluble substitutes for water molecules in the metal-catalyzed hydration of alkynes. The Au-catalyzed addition of boronic acids to alkynes provides an alternative method for enolate generation, which proceeds under exceptionally mild conditions. The resulting enolates can be trapped by aldehydes present in the reaction mixture, giving aldol products that can be isolated as cyclic borate esters. These compounds are versatile synthetic intermediates that can be elaborated into a variety of products by transformation of the boron moiety. The Au-catalyzed reaction of boronic acids with propargylic alcohols results in efficient Meyer-Schuster rearrangement to the corresponding enones. The rearrangement of tertiary alcohols gives $(E)$-enones with moderate to good selectivity, and the addition of a boronic acid to the reaction appears to enhance the level of geometrical control. The rearrangement of primary alcohols to terminal enones also occurs readily in the presence of catalytic $\mathrm{Au}(\mathrm{I})$ and a boronic acid, and the resulting terminal enones can be reacted with nucleophiles in one-pot procedures to give a variety of $\beta$-substituted ketones.
\end{abstract}

Keywords: aldol reactions; alkynes; boron; gold; rearrangements.

\section{INTRODUCTION}

The addition of water across a $\mathrm{C}-\mathrm{C}$ multiple bond is one of the oldest transformations in organic chemistry. It is also one of the simplest and most efficient processes for introducing oxygen functionality into a molecule. The addition of water across an alkene $\mathbf{1}$ leads to the formation of a secondary or tertiary alcohol 2 (Scheme 1). The analogous hydration reaction of an alkyne 3 leads initially to an enol $\mathbf{4}$ that tautomerizes to the corresponding ketone 5 [1].
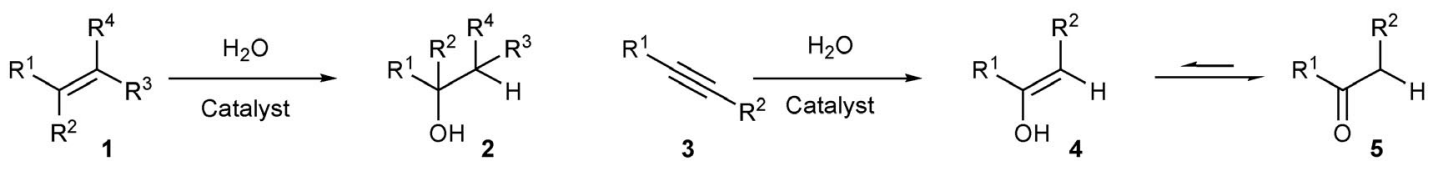

Scheme 1 Catalytic hydration reactions of alkenes and alkynes.

\footnotetext{
*Pure Appl. Chem. 84, 2183-2498 (2012). A collection of invited papers based on presentations at the $14^{\text {th }}$ International Meeting on Boron Chemistry (IMEBORON-XIV), Niagara Falls, Canada, 11-15 September 2011.

‡E-mail: tom.sheppard@ucl.ac.uk
} 
The hydration of an alkene can be catalyzed by strong acids [2], although such conditions are not readily applicable to complex functionalized substrates. Typically, this transformation is achieved via indirect methods such as hydroboration [3] (usually giving the opposite anti-Markovnikov regioselectivity) or via stoichiometric oxymercuration followed by reduction of the resulting organomercury compound [4]. Similarly, the hydration of an alkyne to a methyl ketone was traditionally achieved using a mercury-catalyzed process [4], although nowadays more efficient procedures using less-toxic metals such as Au are the norm [1].

Direct hydration reactions can be problematic due to the fact that most organic compounds are not readily miscible with water. The solvent system for the reaction must thus be carefully chosen in order to enable the organic molecule to react effectively with a water molecule. We became interested in the idea of replacing the water molecule in these reactions with an organic molecule that could act as a water surrogate, enabling the hydration reactions to take place readily in organic solvents. We hypothesized that boronic acids [5] would be suitable for this purpose as the exchange of oxygen groups on the boron is relatively facile, enabling release of the oxygen atom after the boronic acid has undergone reaction with a substrate. They are also stable, readily available molecules that are generally soluble in organic solvents. Boronic acids have previously been exploited as reagents and catalysts for a wide variety of transformations (Fig. 1) [6] including direct amide bond formation (6-9) [7-10], Diels-Alder reactions $(\mathbf{8 , 9})$ [11], Friedel-Crafts reactions (10) [12], rearrangement of propargylic and allylic alcohols (11) [13], aldol reactions (12) [14,15], and the hydrolysis of chlorohydrins (13) [16].
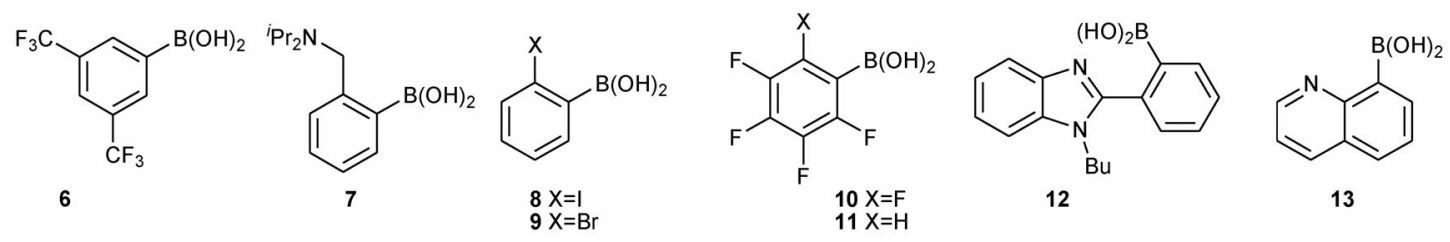

Fig. 1 Selected boronic acid catalysts.

We envisaged that metal-catalyzed addition of a boronic acid to an alkene $\mathbf{1}$ will lead to the boronate ester 14 (Scheme 2). Reaction of this with adventitious moisture can then lead to the alkene hydration product $\mathbf{1 5}$ and regeneration of the boronic acid. In the case of an alkyne $\mathbf{3}$, the intermediate addition product $\mathbf{1 6}$ is a boron enolate [17]. This can potentially be exploited as a reactive intermediate, for example, in an aldol reaction, giving access to a more complex intermediate 17. Again, after hydrolysis of the borate ester with water, the aldol product $\mathbf{1 8}$ will be obtained and the boronic acid will be regenerated.

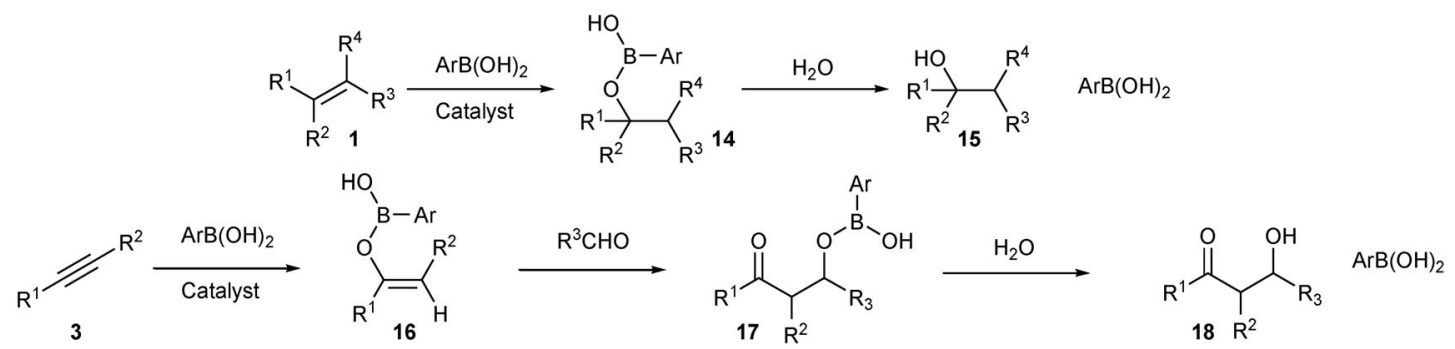

Scheme 2 Proposed pathways for the catalytic addition of boronic acids to alkenes and alkynes. 
We recognized that this latter concept might be especially powerful as it could enable the catalytic generation of a reactive enolate intermediate directly from an unactivated alkyne. This is potentially very useful for aldol reactions as the use of a non-carbonyl enolate precursor can enable chemoselective formation of the desired enolate in the presence of an enolizable aldol acceptor [18].

\section{STABLE BORON ENOLATES}

In order to investigate the feasibility of the proposed enolate formation process, we prepared a series of ortho-alkynylbenzene boronic acids 21 from readily available bromoiodobenzene 19 (Scheme 3) [19].



Scheme 3 Synthesis of ortho-alkynylbenzene boronic acids.

With a series of substrates in hand, we examined the Au-catalyzed [20] cyclization of alkynyl boronic acid 21a (Scheme 4). To our surprise, the boronic acid 21a rapidly cyclized to give a single product 22a. There was no evidence for the formation of the corresponding 5-ring exocyclic product $\mathbf{2 4}$, despite the fact that mixtures of 5- and 6-ring products are typically observed in the corresponding Au-catalyzed cyclization of 2-alkynylbenzoic acids [21,22]. Boronate ester 22a was remarkably stable and could be isolated via chromatography in $85 \%$ yield together with traces of the dimeric species $\mathbf{2 3 a}$. We were able to prepare a series of 1,2-oxaboranaphthalenes 22a-e in good to excellent yield from boronic acids $21 \mathbf{a}-\mathbf{e}$.<smiles>Oc1ccccc1C#CCBr</smiles>

21

<smiles>OB1OC(Br)=Cc2ccccc21</smiles>

22a $85 \%$ 22b $87 \%$<smiles>OB1OC(C2CC2)=Cc2ccccc21</smiles><smiles>OB1OC(Br)=Cc2ccccc21</smiles><smiles>C=C</smiles><smiles>OB1OC(C2=CCCCC2)=Cc2ccccc21</smiles><smiles>CC(C)(C)C(=O)C1=Cc2ccccc2B(OB2OC(C(C)(C)C)=Cc3ccccc32)O1</smiles><smiles>COc1ccc(C2=Cc3ccccc3B(O)O2)cc1</smiles><smiles>OB1OC(=CCBr)c2ccccc21</smiles><smiles>CC1=Cc2ccccc2B(O)O1</smiles>

22e $92 \%$

Scheme 4 Au-catalyzed cyclization of ortho-alkynylbenzene boronic acids. 
One possible reason for the unexpected stability of $\mathbf{2 2}$ is the fact that the boron heterocycle potentially has aromatic character. Related compounds have been reported in the literature as products of a variety of different chemical transformations (Scheme 5) [23-25]. In an early pioneering paper from Letsinger and Nazy [23], it was reported that heating diboronic acid 25 with sodium hydroxide resulted in the formation of a heterocyclic product whose structure was proposed to be $\mathbf{2 6}$ or $\mathbf{2 7}$. In a more recent example, attempted cleavage of the methyl ether in ketone $\mathbf{2 8}$ with $\mathrm{BBr}_{3}$ led to the formation of heterocycle 29 via electrophilic aromatic borylation of the pendent ring [24]. A related approach has been used to synthesize the 9,10-oxaboraphenanthrene system 31 via borylation [26,27] of phenol $\mathbf{3 0}$ with $\mathrm{BCl}_{3}$ and $\mathrm{AlCl}_{3}$ [25]. In light of these latter reactions and our own work, it seems highly likely that the base-mediated cyclization of $\mathbf{2 5}$ also leads to exclusive formation of the stabilized 6-ring boron heterocycle 27 [28], given that the formation of these rings appears to be thermodynamically favorable.<smiles>Oc1ccccc1C#Cc1ccccc1Br</smiles><smiles>O=CC=CON=O</smiles>

then $\mathrm{HCl}$<smiles>CCC(C(=O)c1ccccc1)c1ccccc1</smiles>

30<smiles>OB1OC(=Cc2ccccc2Br)c2ccccc21</smiles><smiles>OB1OC(c2ccccc2Br)=Cc2ccccc21</smiles><smiles>CCC1=C(c2ccc(O)cc2)OB(O)c2ccccc21</smiles><smiles>OB1Oc2ccccc2-c2ccccc21</smiles>

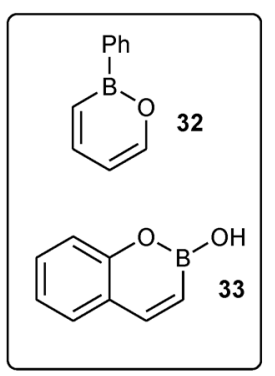

Scheme 5 Previous syntheses of 1,2-oxaboranaphthalenes.

In several theoretical and experimental studies, the aromaticity of these systems has been explored $[25,29,30]$, with one recent study suggesting that there is little evidence for extended aromatic conjugation in the boron heterocycle of compounds such as 31 [30]. The non-fused system 32 was found to exhibit significant aromatic stabilization, however [30]. Notably, some of the fused naphthalene-like systems prepared in our work differ from previous examples in that they do not contain additional aromatic/conjugated substituents on the ring system (e.g., 22a,d,e). Further studies are currently underway in our laboratory in order to explore the aromaticity of these 1,2-oxaboranaphthalenes both experimentally and computationally. It is interesting to speculate about the stability of the closely related system 33 in which the boron and oxygen atoms have been transposed. Although several compounds containing ring systems of general structure $\mathbf{2 2}$ have been prepared, there are no reported compounds containing the bicycle 33 , either with or without substituents. It would be interesting to explore whether such a system could be prepared and characterized, given the stability of compounds $\mathbf{2 2}$. There is substantial interest in the use of boron-oxygen heterocycles in medicinal chemistry [31-34], and the development of synthetic routes to access structurally novel boron-oxygen heterocycles is desirable. 


\section{AN ALTERNATIVE APPROACH TO ALDOL REACTIONS}

In our case, we were interested in whether the 1,2-oxaboranaphthalenes 22 displayed enolate reactivity. We therefore examined the reaction of 22a with butyraldehyde (Scheme 6). Pleasingly, the aldol products $\mathbf{3 4}$ were formed in excellent yield as an 80:20 mixture of diastereoisomers after stirring for several hours at room temperature. The Au-catalyzed enolate formation reaction was sufficiently mild to enable it to be carried out in the presence of the aldehyde, enabling a direct one-pot conversion of $\mathbf{2 1}$ into $\mathbf{3 4}$ in excellent yield. Whilst these cyclic boronates could be isolated by chromatography, they were somewhat unstable if not handled carefully: prolonged drying of a sample of $\mathbf{3 4}$ under high vacuum was found to promote the retro-aldol reaction to regenerate the enolate 22a and volatile butyraldehyde.



Scheme 6 Aldol reactions of boron enolate 22a.

Upon further investigation, it became clear that the aldol products derived from $\mathbf{2 2}$ were not always stable enough to be conveniently isolated. We therefore decided to develop procedures for direct transformation of the cyclic borates to functionalized products, in order to avoid this retro-aldol decomposition reaction. In the first instance we explored a $\mathrm{Cu}$-catalyzed protodeboronation [35] of the cyclic boronates 35 to generate known hydroxyketones 36 (Scheme 7) [36] in order to determine the stereochemistry of the major aldol product. By comparison of the NMR data with the literature, the major aldol product was identified as anti-36. This sequence demonstrates the mildness of the enolate formation conditions: the Au-mediated enolate generation can even be carried out in the presence of highly reactive acetaldehyde, and a selective crossed-aldol reaction was achieved without needing to use a preformed enolate derivative such as a silyl enol ether or metal enolate.
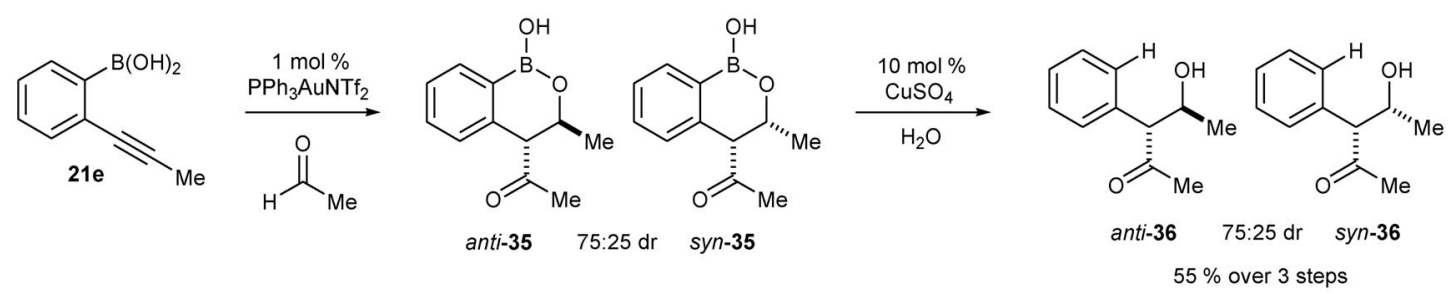

Scheme 7 Au-catalyzed enolate formation/aldol reaction of 21e and subsequent protodeboronation.

We also developed procedures for the oxidation of cyclic borates 37 to give phenols $\mathbf{3 8}$ [37], for Suzuki cross-coupling to give biaryls $\mathbf{3 9}$ and for Cu-catalyzed intramolecular Chan-Lam coupling [38] to give 2,3-dihydrobenzofurans 40 (Scheme 8) [39]. The resulting products were obtained in good to excellent yields over the multistep reaction sequences and with moderate diastereoselectivity.

This formation of $\mathbf{4 0}$ is particularly noteworthy as it constitutes the first example of an intramolecular Chan-Lam coupling [38] of an aliphatic alcohol. Typically, these couplings are rarely successful with aliphatic alcohols as the nucleophilic component [40,41]. However, in our case the reaction not only takes place in good yield but only requires a relatively low catalyst loading. 


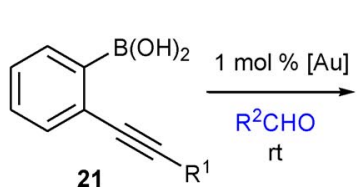

21<smiles>[R]C(=O)[C@H]1c2ccccc2OC1[R]</smiles><smiles>[R]C(=O)[C@H]1c2ccccc2B(O)OC1[R]</smiles><smiles>CCCCC</smiles><smiles>[R10]Oc1ccccc1C(C([R])=O)C([R2])O[R]</smiles>

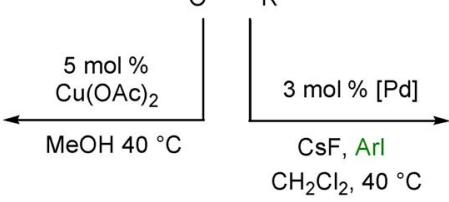<smiles>[R1]C(=O)[C@H](c1ccccc1Br)C([R])O</smiles>

39<smiles>CCCC[C@@H](C(C)=O)C(=O)Oc1ccccc1C(=O)C1=CCCCC1</smiles>

$65 \%, 75: 25 \mathrm{dr}$<smiles>CC(=O)Oc1ccccc1[C@@H](C(=O)Br)[C@@H](OC(C)=O)c1ccccc1[N+](=O)[O-]</smiles>

$99 \%, 45: 55 \mathrm{dr}$

$97 \%$ yield, $67: 33 \mathrm{dr}$

$98 \%$ yield, $67: 33 \mathrm{dr}$

$70 \%$ yield, $67: 33 \mathrm{dr}$<smiles>Cc1ccc(-c2ccccc2C(C(=O)C2CC2)C(C)O)cc1</smiles>

$74 \%, 62: 38 d r$<smiles>CCC[C@H]1Oc2ccccc2C1C(=O)C(=O)c1ccccc1</smiles>

$75 \%, 79: 21 \mathrm{dr}$<smiles>C[C@@H]1Oc2ccccc2C1C(=O)C1CC1</smiles>

$81 \%, 66: 34 \mathrm{dr}$

Scheme 8 Au-catalyzed enolate formation/aldol reactions of boronic acids $\mathbf{2 1}$ and subsequent transformations of the boron group to give phenols 38, biaryls 39, and 2,3-dihydrobenzofurans $\mathbf{4 0}$.

During the course of our investigations, we also examined the reaction of boronic acid $\mathbf{2 1 b}$ with the dimethyl acetal of benzaldehyde in the presence of a Au catalyst, hoping to obtain the methyl ether 41 (Scheme 9). However, the acetal was slowly hydrolyzed under the reaction conditions releasing benzaldehyde, which then underwent aldol reaction with the enolate derived from $\mathbf{2 1 b}$ to give product 42. Curiously, the syn product (syn-42) was obtained as the major diastereoisomer in contrast to the corresponding reaction with the free aldehyde. Carrying out the aldol reaction with $\mathrm{PhCHO}$ in the presence of 2 equiv of $\mathrm{MeOH}$ also led to the formation of syn-42 as the major isomer, but a much higher conversion was observed in comparison to direct reaction with the acetal. This is presumably because hydrolysis of the acetal is relatively slow under the reaction conditions, leading to a much lower concentration of $\mathrm{PhCHO}$.
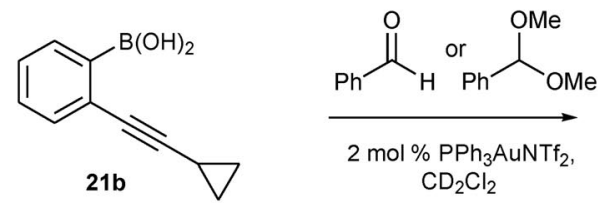
$\mathrm{CD}_{2} \mathrm{Cl}_{2}$<smiles>O=C(C1CC1)[C@H]1c2ccccc2B(O)O[C@H]1c1ccccc1</smiles>

PhCHO: $1 \mathrm{~h}, 93 \%$ conversion, $63.37 \mathrm{dr}$ $\mathrm{PhCH}(\mathrm{OMe})_{2}: 3.5 \mathrm{~h}, 53 \%$ conversion, $34: 66 \mathrm{dr}$ $\mathrm{PhCHO} / 2$ eq. $\mathrm{MeOH}: 3 \mathrm{~h}, 91 \%$ conversion 34:66 dr<smiles>COC(c1ccccc1)C1c2ccccc2B(O)OC1(O)C1CC1</smiles>

41

Scheme 9 Au-catalyzed enolate formation/aldol reactions of $\mathbf{2 1 b}$ with $\mathrm{PhCHO}$ and $\mathrm{PhC}(\mathrm{OMe})_{2}$. 
These observations are somewhat puzzling as they suggest that the presence of $\mathrm{MeOH}$ is somehow able to invert the stereoselectivity of the reaction. It is possible that the presence of methanol leads to a different reaction pathway, or that methanol can either promote or inhibit equilibration of the borate isomers $\mathbf{4 2}$ to give a thermodynamic product mixture. Mechanistic studies are currently underway in order to elucidate the reason for these unusual observations.

\section{GOLD-CATALYZED REACTION OF BORONIC ACIDS WITH PROPARGYLIC ALCOHOLS}

We next explored the intermolecular reaction of boronic acid $\mathbf{4 3}$ with propargylic alcohol $\mathbf{4 4}$ in the presence of a Au catalyst and an aldehyde (Scheme 10). However no aldol reaction occurred and the major product of this reaction was enone 45, the result of a Au-catalyzed Meyer-Schuster rearrangement [42] of propargylic alcohol 44 [43].

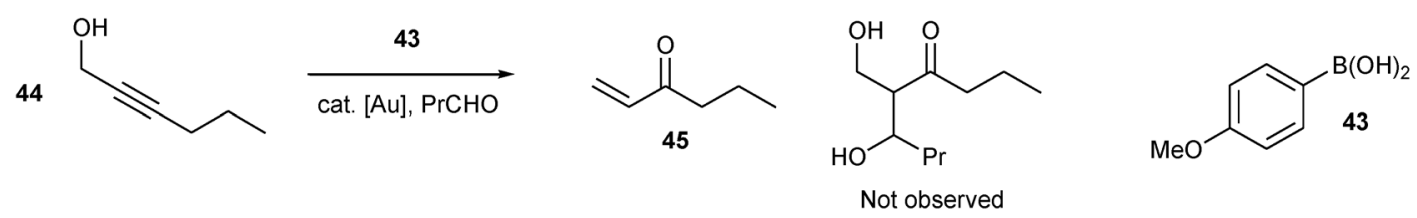

Scheme 10 Attempted Au-catalyzed enolate formation/aldol reaction from a propargylic alcohol.

This rearrangement reaction was extremely rapid, taking place in a few hours at room temperature in the presence of Au catalyst and a catalytic quantity of boronic acid. Whilst there are numerous reports of the Au-catalyzed Meyer-Schuster rearrangement of propargylic alcohols [44-49], many of these reactions are carried out in $\mathrm{MeOH}$ as solvent and require heating for prolonged periods. Under our optimized conditions, the rearrangement of a wide range of propargylic alcohols $\mathbf{4 6}$ could be achieved at room temperature using $2 \mathrm{~mol} \%$ Au catalyst in toluene, in the presence of either $20 \mathrm{~mol} \%$ of boronic acid $\mathbf{4 3}$ or 1 equiv of $\mathrm{MeOH}$ as an additive (Scheme 11) [43,50].

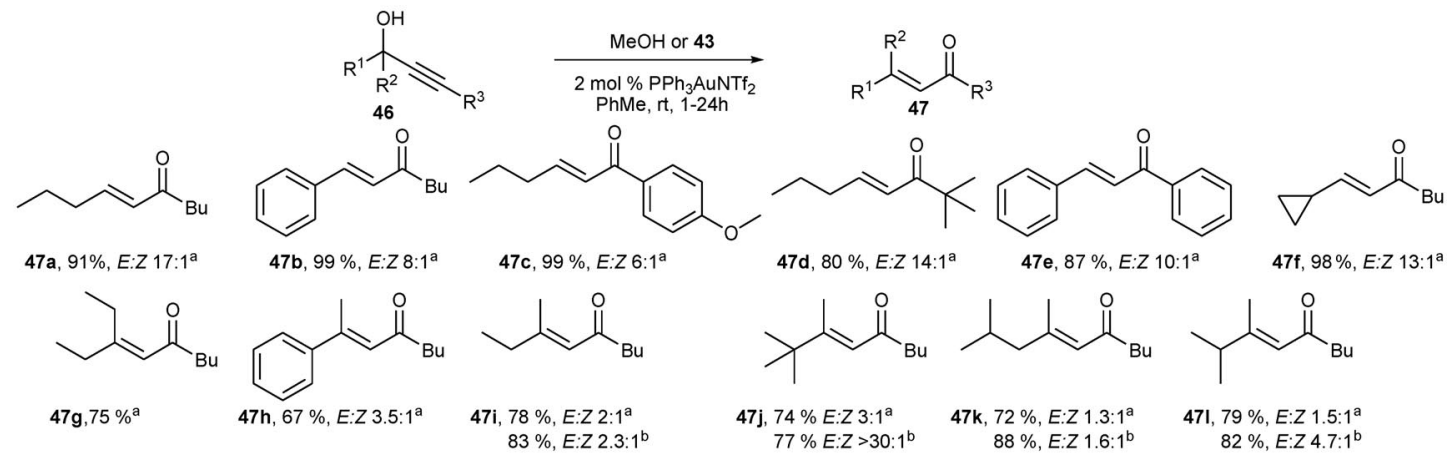

Scheme 11 Au-catalyzed Meyer-Schuster rearrangement of propargylic alcohols in the presence of additives; ${ }^{a}$ With 1 equiv $\mathrm{MeOH}$ as the additive; ${ }^{\text {bWith }} 0.2$ equiv $\mathbf{4 3}$ as the additive.

The resulting enones 47 were produced in good to excellent yield with the $(E)$-isomer being predominant in each case. Interestingly, whilst using $\mathrm{MeOH}$ as the additive generally led to higher yields for the rearrangement of secondary propargylic alcohols, the boronic acid additive was more effective for the rearrangement of tertiary alcohols, giving the products in slightly higher yield and with an enhanced $(E: Z)$ ratio. This is particularly notable for compound $\mathbf{4 7} \mathbf{j}$ where the boronic acid conditions 
give a significant enhancement in the $(E: Z)$ ratio. Interestingly, the boronic acid appears to accelerate isomerization of the enone to the more stable isomer. Upon addition of boronic acid $\mathbf{4 3}$ to a rearrangement reaction carried out with $\mathrm{MeOH}$ as the additive, the $(E: Z)$ ratio of the enone product $\mathbf{4 7 \mathbf { j }}$ increased over the course of $6 \mathrm{~h}$ from 3:1 to 30:1 (Scheme 12) [50].<smiles>CC(C)(C)C(C)(O)C#CBr</smiles>

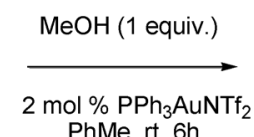

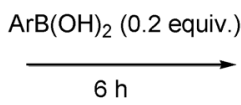

47j $E: Z 3: 1$

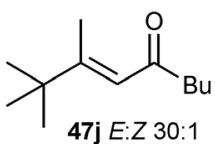

Scheme 12 Enhancement of the $E: Z$ ratio of enone $\mathbf{4 7} \mathbf{j}$ by addition of a boronic acid.

In combination with the addition of an alkyne nucleophile to an aldehyde or ketone, the Meyer-Schuster rearrangement provides a highly effective method for the synthesis of enones, which avoids the need for Wittig-type olefination reactions that produce stoichiometric byproducts. As can be seen in the above examples, the reaction is high yielding and generally proceeds with good control over the geometry of the resulting enone.

The rearrangement of primary alcohols $\mathbf{4 9}$ is particularly difficult due to the high reactivity of the resulting terminal enones $\mathbf{5 0}$. In the presence of $\mathrm{MeOH}$, either as solvent or additive, the terminal enone $\mathbf{5 0}$ readily undergoes addition of $\mathrm{MeOH}$ to generate significant quantities of $\mathbf{5 1}$ (Scheme 13). Both of these compounds are somewhat unstable, and their isolation via chromatography is difficult.
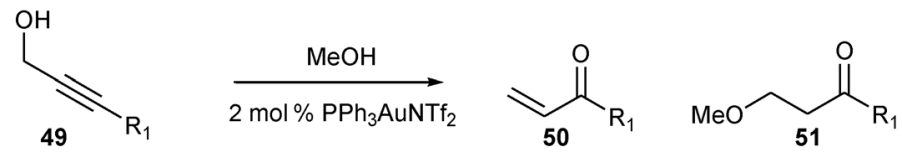

Scheme 13 Meyer-Schuster rearrangement of a primary propargylic alcohol in the presence of $\mathrm{MeOH}$.

However, using boronic acid $\mathbf{4 3}$ as the additive, the enone $\mathbf{5 0}$ is generated cleanly and can be used directly in subsequent reactions. For example, we carried out the rearrangement reaction followed by the Pd-catalyzed addition of the boronic acid to the terminal enone to provide $\beta$-arylketones $\mathbf{5 2}$ directly in one-pot (Scheme 14) [43].

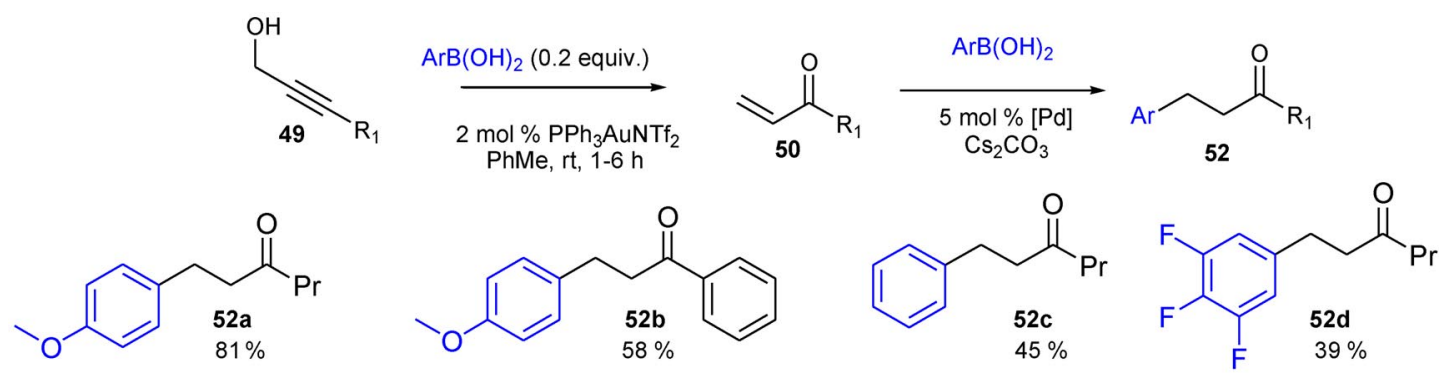

Scheme 14 One-pot Meyer-Schuster rearrangement of primary propargylic alcohols and subsequent Pd-catalyzed boronic acid addition.

Similarly, the addition of an oxygen, nitrogen, or sulfur nucleophile to the terminal enone can be readily achieved by simply adding it to the reaction mixture after the rearrrangement reaction is com- 


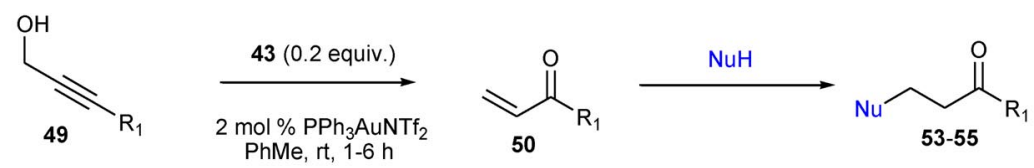

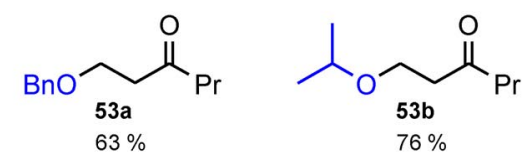

<smiles>CCCC(=O)CCN1CCOCC1</smiles><smiles>CCCCCCCCCCCCCCCCCCC</smiles>

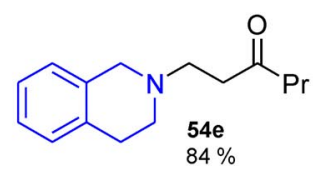<smiles>CCCCCCC(=O)CCN(C)c1ccccc1</smiles>

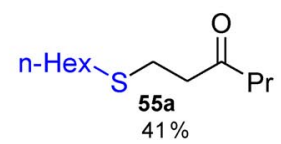

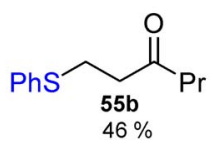

Scheme 15 One-pot Meyer-Schuster rearrangement of primary propargylic alcohols and subsequent addition of nucleophiles.

plete (Scheme 15). This provides access to $\beta$-alkoxy, $\beta$-amino, and $\beta$-sulfido ketones 53-55 directly in one-pot from readily available primary propargylic alcohols [50].

The exact role of the protic additive ( $\mathrm{MeOH}$ or boronic acid $\mathbf{4 3}$ ) in these reactions is not immediately obvious. A plausible mechanism for the rearrangement is shown in Scheme 16. Coordination of the $\mathrm{Au}(\mathrm{I})$ cation to the alkyne, directed by the adjacent alcohol, enables nucleophilic attack of an oxygen nucleophile $\left(\mathrm{H}_{2} \mathrm{O}, \mathrm{MeOH}\right.$, or 43) to give enol 56. After proton transfer to the alcohol group, loss of water can occur assisted by either the enol (58) or the $\mathrm{C}-\mathrm{Au}$ bond (59). Protodeauration of $\mathbf{5 8}$ will lead to the oxonium ion $\mathbf{6 0}$, which can undergo hydrolysis to give the enone product $\mathbf{4 7}$. Alternatively, if water is the nucleophile $(\mathrm{X}=\mathrm{H}), \mathbf{5 8}$ can be transformed directly into $\mathbf{4 7}$ by protodeauration. Allenyl ether $\mathbf{5 9}$ can be converted into the enone product $\mathbf{4 7}$ by hydrolysis, potentially with further assistance from the Au catalyst. Although it is tempting to invoke cyclic intermediates such as $\mathbf{6 1}$ for the boronic acid-assisted rearrangement, there is currently no evidence to support this. In addition, the experiment shown in Scheme 12 suggests that the higher level of geometrical control observed in the boronic acidmediated reactions is likely to arise from equilibration of the product enone 47, rather than from differences in the mechanism of the rearrangement reaction itself.

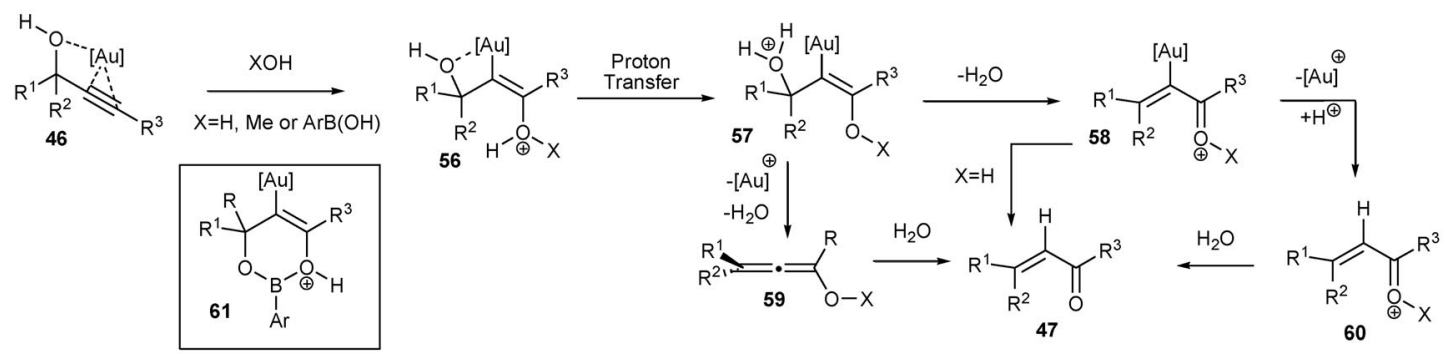

Scheme 16 Possible mechanism for the Meyer-Schuster rearrangement in the presence of protic additives.

\section{SUMMARY}

The Au-mediated reaction of boronic acids with alkynes has been demonstrated to provide access to a wide variety of useful products including novel boron heterocycles, functionalized aldol products, 2,3-dihydrobenzofurans, trisubstituted enones, and $\beta$-functionalized ketones (Scheme 17). In these reactions, the boronic acid moiety serves as an organic-soluble water equivalent, facilitating the Au-cat- 


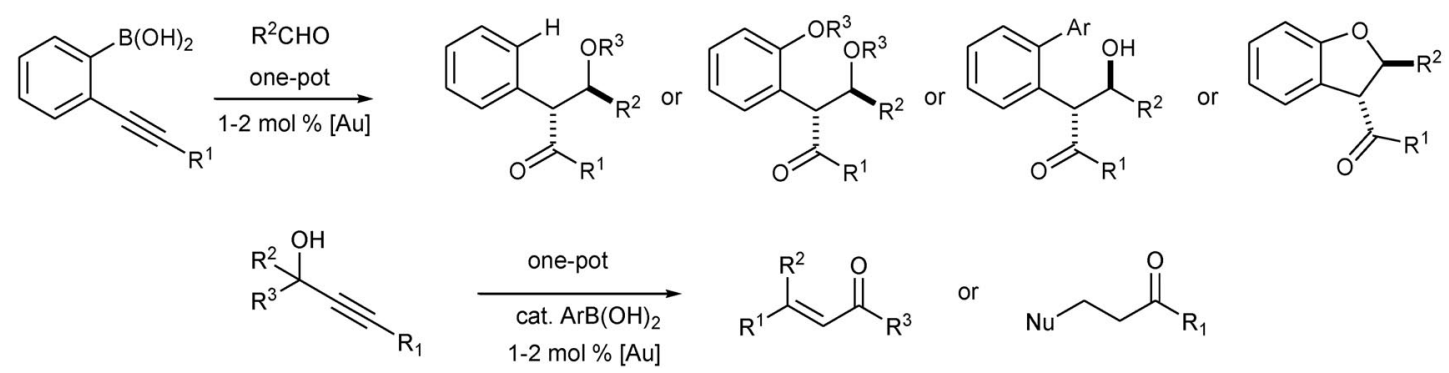

Scheme 17 Synthesis of diverse functionalized products via Au-catalyzed reaction of boronic acids with alkynes.

alyzed hydration reaction. Further work is underway in our group to extend these "complexity-generating" hydration reactions to a wide range of synthetic applications.

\section{ACKNOWLEDGMENTS}

I would like to thank the EPSRC for supporting my research through the award of an Advanced Research Fellowship (EP/E052789/1).

\section{REFERENCES}

1. L. Hintermann, A. Labonne. Synthesis 1121 (2007).

2. V. J. Nowlan, T. T. Tidwell. Acc. Chem. Res. 10, 252 (1977).

3. C. M. Crudden, D. Edwards. Eur. J. Org. Chem. 4695 (2003).

4. M. Nishizawa, H. Imagawa, H. Yamamoto. Org. Biomol. Chem. 8, 511 (2010).

5. D. G. Hall (Ed.). Boronic Acids, Wiley-VCH, Weinheim (2011).

6. I. Georgiou, G. Ilyashenko, A. Whiting. Acc. Chem. Res. 42, 756 (2009).

7. R. M. Al-Zoubi, O. Marion, D. G. Hall. Angew. Chem., Int. Ed. 47, 2876 (2008).

8. K. Ishihara, S. Ohara, H. Yamamoto. J. Org. Chem. 61, 4196 (1996).

9. K. Arnold, A. S. Batsanov, B. Davies, A. Whiting. Green Chem. 10, 124 (2008).

10. P. Starkov, T. D. Sheppard. Org. Biomol. Chem. 9, 1320 (2011).

11. H. Zheng, D. G. Hall. Tetrahedron Lett. 51, 3561 (2010).

12. J. A. McCubbin, H. Hosseini, O. V. Krokhin. J. Org. Chem. 75, 959 (2010).

13. H. Zheng, M. Lejkowski, D. G. Hall. Chem. Sci. 2, 1305 (2011).

14. D. Lee, S. G. Newman, M. S. Taylor. Org. Lett. 11, 5486 (2009).

15. K. Aelvoet, A. S. Batsanov, A. J. Blatch, C. Grosjean, L. G. F. Patrick, C. A. Smethurst, A. Whiting. Angew. Chem., Int. Ed. 47, 768 (2008).

16. R. L. Letsinger, S. H. Dandegaonker. J. Am. Chem. Soc. 81, 498 (1959).

17. M. Murakami, T. Mukaiyama. Chem. Lett. 11, 241 (1982).

18. T. D. Sheppard. Synlett 1340 (2011).

19. C. Körner, P. Starkov, T. D. Sheppard. J. Am. Chem. Soc. 132, 5968 (2010).

20. N. Mézailles, L. Ricard, F. Gagosz. Org. Lett. 7, 4133 (2005).

21. H. Aikawa, S. Tago, K. Umetsu, N. Haginiwa, N. Asao. Tetrahedron 65, 1774 (2009).

22. E. Marchal, P. Uriac, B. Legouin, L. Toupet, P. van de Weghe. Tetrahedron 63, 9979 (2007).

23. R. L. Letsinger, J. R. Nazy. J. Am. Chem. Soc. 81, 3013 (1959).

24. V. L. Arcus, L. Main, B. K. Nicholson. J. Organomet. Chem. 460, 139 (1993).

25. L. M. Greig, B. M. Kariuki, S. Habershon, N. Spencer, R. L. Johnston, K. D. M. Harris, D. Philp. New J. Chem. 26, 701 (2002). 
26. A. Del Grosso, M. D. Helm, S. A. Solomon, D. Caras-Quintero, M. J. Ingleson. Chem. Commun. 47, 12459 (2011).

27. A. Del Grosso, P. J. Singleton, C. A. Muryn, M. J. Ingleson. Angew. Chem., Int. Ed. 50, 2102 (2011).

28. R. L. Letsinger, T. E. Feare, T. J. Savereide, J. R. Nazy. J. Org. Chem. 26, 1271 (1961).

29. R. M. Minyaev, V. I. Minkin, T. N. Gribanova, A. G. Starikov. Mendeleev Commun. 11, 43 (2001).

30. J. Chen, Z. Bajko, J. W. Kampf, A. J. Ashe III. Organometallics 26, 1563 (2007).

31. S. J. Baker, J. W. Tomsho, S. J. Benkovic. Chem. Soc. Rev. 40, 4279 (2011).

32. X. Li, J. J. Plattner, V. Hernandez, C. Z. Ding, W. Wu, Y. Yang, M. Xu. Tetrahedron Lett. 52, 4924 (2011).

33. S. J. Baker, Y. -K. Zhang, T. Akama, A. Lau, H. Zhou, V. Hernandez, W. Mao, M. R. K. Alley, V. Sanders, J. J. Plattner. J. Med. Chem. 49, 4447 (2006).

34. Y.-K. Zhang, J. J. Plattner, Y. R. Freund, E. E. Easom, Y. Zhou, J. Gut, P. J. Rosenthal, D. Waterson, F.-J. Gamo, I. Angulo-Barturen, M. Ge, Z. Li, L. Li, Y. Jian, H. Cui, H. Wang, J. Yang. Bioorg. Med. Chem. Lett. 21, 644 (2011).

35. A. D. Ainley, F. Challenger. J. Chem. Soc. 2171 (1930).

36. T. Mukaiyama, K. Banno, K. Narasaka. J. Am. Chem. Soc. 96, 7503 (1974).

37. J. R. Falck, M. Bondlela, S. K. Venkataraman, D. Srinivas. J. Org. Chem. 66, 7148 (2001).

38. J. X. Qiao, P. Lam. Synthesis 829 (2011).

39. T. D. Sheppard. J. Chem. Res. 35, 377 (2011).

40. T. D. Quach, R. A. Batey. Org. Lett. 5, 1381 (2003).

41. R. E. Shade, A. M. Hyde, J.-C. Olsen, C. A. Merlic. J. Am. Chem. Soc. 132, 1202 (2010).

42. D. A. Engel, G. B. Dudley. Org. Biomol. Chem. 7, 4149 (2009).

43. M. N. Pennell, M. G. Unthank, P. Turner, T. D. Sheppard. J. Org. Chem. 76, 1479 (2011).

44. D. Wang, Y. Zhang, A. Harris, L. N. S. Gautam, Y. Chen, X. Shi. Adv. Synth. Catal. 353, 2584 (2011).

45. D. A. Engel, S. S. Lopez, G. B. Dudley. Tetrahedron 64, 6988 (2008).

46. S. I. Lee, J. Y. Baek, S. H. Sim, Y. K. Chung. Synthesis 2107 (2007).

47. L. Ye, L. Zhang. Org. Lett. 11, 3646 (2009).

48. M. Egi, Y. Yamaguchi, N. Fujiwara, S. Akai. Org. Lett. 10, 1867 (2008).

49. R. S. Ramón, N. Marion, S. P. Nolan. Tetrahedron 65, 1767 (2009).

50. M. N. Pennell, P. G. Turner, T. D. Sheppard. Chem.—Eur. J. 18, 4748 (2012). 